DOI 10.37882/2223-2982.2020.10.13

\title{
СОВРЕМЕННЫЙ ОПЫТ РАЗВИТИЯ КРЕАТИВНОСТИ ДИЗАЙНЕРОВ В УСЛОВИЯХ КУЛЬТУРНО-ДОСУГОВОЙ ДЕЯТЕЛЬНОСТИ
}

\section{MODERN EXPERIENCE \\ IN THE DEVELOPMENT OF CREATIVITY OF DESIGNERS IN THE CONDITIONS OF CULTURAL AND LEISURE ACTIVITIES}

E. Galiullina

Summary: The article examines the modern foreign and domestic experience in the development of creativity in the context of cultural and leisure activities on the example of the most popular leisure modules for the development of creativity. The classification of leisure modules for the development of creativity has been formulated. The general principles of creativity development are outlined, which are universal for most leisure modules.

Keywords: creativity, leisure modules for the development of creativity, online courses for the development of creativity, principles for the development of creativity.

\author{
Галиуллина Эльмира Ринатовна \\ Преподаватель, Казанский государственный институт \\ культуры \\ galiullina_er@kazgik.ru
}

Аннотация: В статье рассмотрен современный зарубежный и отечественный опыт развития креативности в условиях культурно-досуговой деятельности на примере самых востребованных досуговых модулей развития креативности. Сформулирована классификация досуговых модулей развития креативности. Обозначены общие принципы развития креативности, которые являются универсальными для большинства досуговых модулей.

Ключевые слова: креативность, досуговые модули развития креативности, онлайн-курсы развития креативности, принципы развития креативности. рофессия дизайнера значительно зависит от состояния современной экономики и тенденций в обществе. Вследствие этого для продуктивной деятельности дизайнер должен обладать гибким мышлением, быть способен к продуктивному реагированию на быстроменяющиеся условия жизни, где нужно ориентироваться в ситуациях неопределенности и принимать нетрадиционные решения. Способностью, которая напрямую влияет на эти качества является креативность. Получение высшего образования является основой в развитии способностей дизайнеров, в последующей же профессиональной деятельности дизайнер может продолжить свое развитие в системе дополнительного образования или досуга. В связи с этим, представляется актуальным изучение современного зарубежного и отечественного опыта культурно-досуговых модулей развития креативности на примере самых востребованных мировых досуговых модулей развития креативности в сети интернет за период 2018-2020 годы, что является целью нашего исследования.

Известно о необходимости формирования дизайнерами своего уникального опыта в области дизайн-образования, что возможно через активное построение индивидуальных образовательных и самореализационных маршрутов. Саморазвитие дизайнеров в более свободной и гибкой форме происходит в условиях культурно- досуговой деятельности. В наибольшей степени досуговые модули по развитию креативности представляют собой курсы, тренинги, семинары, либо факультативы при вузах [15].

На сегодняшний день существует множество культурно-досуговых модулей развития креативности и их можно классифицировать по возрасту и роду деятельности участников. Известны культурно-досуговые модули развития креативности, которые классифицируются по возрасту участников и направлены на:

- участников любых возрастов;

- детей дошкольного возраста;

- детей младшего школьного возраста;

- подростков;

- молодёжь;

- универсальные модули, ориентированные на семьи с детьми и т.д.

Классификация культурно-досуговых модулей развития креативности по роду деятельности представляет собой:

- универсальные модули, направленные на представителей любых профессий;

- модули, направленные на ученых в различных областях, в сфере инноваций;

- на руководителей и деятелей бизнеса и т.д. 
- общие модули, направленные на представителей творческих профессий;

- модули, направленные на фотографов, писателей, актеров, режиссеров, художников и т.д.;

- модули, направленные на графических дизайнеров, дизайнеров среды или интерьера, промышленных, текстильных, ландшафтных дизайнеров и т.д.

Предметом нашей работы являются культурно-досуговые модули, направленные на дизайнеров. Среди культурно-досуговых модулей развития креативности универсальными мы называем те модули, которые не зависят от профессиональной принадлежности и направлены на любых участников, независимо от возраста, пола и сферы деятельности. Подобные культурно-досуговые модули дают общее представление о методах развития креативности и носят ознакомительный характер. Например, The Creative Course (Творческий курс) был создан в 1993 году педагогом и писателем Shelley BERC и педагогом и мультимедиа-художником Alejandro Fogel [22]. Организаторы модуля создают особую атмосферу, где любой человек может раскрыть свои способности. Ведущие данного модуля помогают участникам раскрыть собственный потенциал. Работая вне своей специальности и выходя из зоны своего комфорта, участники освобождаются от сковывающего их перфекционизма и получают свободу для экспериментирования, совершения ошибок и получения нового опыта. Когда люди осознают свой творческий потенциал, они хотят его использовать и выражать это своим собственным уникальным способом, заставляя его работать на них [5]. Таким образом повышается активность и личная заинтересованность собственным развитием.

Подобного рода культурно-досуговых модулей по развитию креативности множество. Их можно рекомендовать дизайнерам для ознакомления с основами креативного мышления, для групповой работы с представителями других профессий, что может стать неким импульсом и «свежим дыханием» в профессиональной деятельности дизайнера.

- Следующие культурно-досуговые модули, которые направлены на деятелей искусства, например, художников, фотографов, писателей, музыкантов, актеров, дизайнеров и т.д. Одним из таких культурно-досуговых модулей является курс Джима Сазерленда: «Дизайн, Работа и Игра», где участники генерируют идеи с помощью упражнений, используя игровую среду и опираясь на опыт в профессиональной сфере [21]. Организаторы считают главным условием создание игровой атмосферы, которая будет противоположна работе. Таким образом, участники воспринимают рабочую ситуацию как игру и легче и с энтузиазмом решают поставленные задачи. Игровая атмосфера помо- гает добиться повышения мотивации развиваться участников, а это в свою очередь способствует повышению продуктивности культурно-досугового процесса. Таким образом, эмоционально-насыщенный социокультурный процесс положительно воздействует на развитие личности в целом и на развитие креативности в частности.

К более узким по направленности культурно-досуговым модулям развития креативности можно отнести модуль Кит Ларсон - «Искусство и наука убеждений» [17] и Александра Тейлор «продажи» [11]. В своих модулях авторы знакомят с методами развития креативности в производстве рекламы и в продажах. Несколько иной по направленности культурно-досуговый модуль Алекс Лампе - «Реклама в цифровом искусстве», в котором участников знакомят с методами генерации идей в рекламе с помощью цифровых технологий [14]. Все три рассмотренных модуля имеют акцент на «продажи». Эта сфера тесно пересекается со сферой дизайна. Искусство убеждения покупателей товара, его реклама являются частью работы дизайнера. Интересно отметить последовательность изложения и освоения материала в данных модулях, а именно, на занятиях происходит равномерное знакомство с материалом от общих вопросов теории дизайна к более узким вопросам связанным с кейсами из сферы продаж.

Следующий культурно-досуговый модуль, относящийся к брендингу, курс Майкла Джонсона [9] развивает креативность в разработке брендов компаний, в отличие от курса Марии Эйзагуирр Диегес [15], в котором изучаются основы психологии в формировании бренда компании, где основной акцент идет на восприятие брендов. Кроме того, существуют культурно-досуговые модули развития креативности, которые направлены на создание уникальных изделий в декоративно-прикладном искусстве, например, курс Александры Тейлор - «Искусство в художественном направлении» [12]. Данный курс имеет последовательную расширенную программу, в отличие от большинства модулей, которые являются краткосрочными.

Таким образом, существуют культурно-досуговые модули, которые в рамках основной цели, заключающейся в развитии креативности, имеют свою более узкую специфику в зависимости от целей, которые преследует участник досугового процесса. Некоторые досуговые модули имеют более теоретическую направленность, некоторые предполагают процесс эскизирования дизайн-продуктов, целью других является изготовление готового изделия или запуск проекта в производство. Мы же считаем наиболее продуктивными культурно-досуговые модули, которые включают в себя значительное количество практических упражнений под руководством наставника. Но при этом практическим занятиям 
должны предшествовать теоретические. Это необходимо для лучшего последовательного и системного усвоения программы.

Культурно-досуговые модули для руководителей организаций и бизнесменов могут быть использованы дизайнерами-руководителями проектов или дизайнерами-одиночками, которые собственноручно занимаются собственным продвижением. К такого рода модулям отнесем курс Патрика Коллистера, который создал курс по генерации бизнес-идей, где он опирается на современное состояние экономики и учит создавать идеи, которые бы способствовали эффективной продаже продукта, учитывая современную экономическую ситуацию [13]. Данный курс дополнен теоретической информацией и кейсами из сферы экономики. Похожим культурнодосуговым модулем является «Творческое мышление и решение проблем», который преподается в Сиднее, знакомит участников с методиками и инструментами творческого мышления для решения проблем, управления рисками, принятия решений и освоением ресурсов [18]. Этот курс подходит для менеджеров, руководителей, и тех, кто хочет познакомиться с принципами творческого мышления, этапами творческого процесса. Кроме того, при прохождении данного культурно-досугового модуля участники учатся определять первопричину проблемы, что делает процесс решения проблем более эффективным. Таким образом, культурно-досуговые модули по развитию креативности руководителей включают в себя теоретическую часть с ознакомлением с основами работы креативного мышления, принципами творческого мышления, этапами творческого процесса, связи креативности и современной экономики и практическую часть с освоением методом генерации идей. Подобный блок культурно-досуговых модулей может быть использован дизайнерами-руководителями проектов, для лучшей интеграции дизайна в условия современной экономики, для актуализации и запуска дизайн-продукта.

Следующий рассмотренный культурно-досуговый модуль, направленный на преподавателей, создан доктором Робертом Келли из Университета Калгари и доктором Карлом Легго из Университета Британской Колумбии, который ориентирован не только на преподавателей, но и на всех лиц, которым интересно изучать творческое развитие учащихся с раннего детства до высшей школы. Участники данного модуля получают общие представления о процессе творческого мышления, его этапах и особенностях развития креативности [23]. Культурно-досуговые модули по развитию креативности направленные на преподавателей, занятых в подготовке будущих дизайнеров помогут педагогам понять основы работы креативного мышления для более продуктивной педагогической деятельности в подготовке дизайнеров и выстраивания преемственности, последовательности, и системности процесса развития креативности дизай- неров.

Культурно-досуговый модуль «Стратегическое творческое развитие», преподается Эдвардом Бошем в Бостонском университете и является довольно прогрессивным для нашего времени [16]. В этом курсе участники изучают, анализируют и генерируют идеи, с использованием традиционной рекламы, приложений в социальных медиа, цифровых платформ, мобильных приложений и игр. При этом в разработке бренда используются технологии, которые воздействуют на потребителя. В данном модуле используются не только традиционные для других модулей графические принадлежности, но и работа в гаджетах. Данный аспект предполагает подготовленную аудиторию дизайнеров, обладающих навыками работы в графических программах.

Культурно-досуговый модуль развития креативности в Профессиональном училище Австралии Чисхолм направлен на художников, иллюстраторов и фотографов [10]. Модуль является личностно-ориентированным и направлен на развитие и укрепление творческих, предпринимательских и маркетинговых навыков. Кроме практических занятий, участникам читаются лекции о направлениях глобального дизайна, презентации проекта, по работе с заказчиком, управлению, маркетингу, авторскому праву, разработке инновационных продуктов, реализации проектных решений.

Таким образом, большинство культурно-досуговых модулей по развитию креативности интегрированы в другие сферы деятельности участников и включают дополнительные досуговые модули связанные со спецификой работы в разных областях дизайна, науки и техники, что способствует более разностороннему развитию личности дизайнера.

Кроме культурно-досуговых модулей развития креативности, где необходимо очное участие, существует множество онлайн-курсов, которые являются альтернативой для людей, которые по каким-либо причинам не могут участвовать лично, но работают над самосовершенствованием [1]. Одним из таких онлайн-курсов является «Творческий курс по разработке концепций», разработанный Кристен Беккер [20]. Курс содержит несколько блоков, таких как: «планирование творчества», «вдохновение, мозговые штурмы и решение», «ведение процесса проектирования Fresh» «презентация», «рабочий процесс», «окончательный дизайн и производство запуска». Подобного рода культурно-досуговые модули несмотря на меньшую эффективность по сравнению с культурно-досуговыми модулями по развитию креативности очного формата, становятся более востребованы. Это связано с нестабильностью в мире, которую показал 2020 год, с более мобильным образом жизни современного человека, когда нет желания тратить время на 
передвижения, и с возможностью развиваться в любое время в соответствии с личными потребностями, что как раз характеризует культурно-досуговую сферу.

Подводя итоги по анализу зарубежного опыта развития креативности дизайнеров в условиях культурно-досуговой деятельности выделим основные, свойственные практически всем зарубежным культурно-досуговым модулям развития креативности принципы, среди которых: активное участие, целостность и этапность образовательного процесса, органичное совмещение коллективной и индивидуальной деятельности, личностно-ориентированный подход к участникам, ориентация на эмоцию как стимул деятельности, игровая атмосфера, использование креативного мышления не только в учебной деятельности, но и в повседневной жизни.

Анализ зарубежных культурно-досуговых модулей развития креативности показал большой спрос и множество предложений по направлениям, специфике и форме участия, в отличие от российского опыта, где культурно-досуговых модулей по развитию креативности относительно немного. Рассмотрим тренинг «Искусство нестандартных решений», целью которого является осознание креативности в себе и ее развитие [5]. Данный модуль относится к универсальным и подходит для тех людей, чья успешная профессиональная деятельность напрямую зависит от нестандартного мышления и умения выйти за рамки привычного восприятия и автоматических действий. Следующий рассматриваемый нами тренинг проводится в Казани в центре подготовки персонала «Фактор-П» и называется «Искусство нестандартно мыслить» [6]. Данный модуль предполагает создание эмоционально-насыщенного социокультурного процесса развития креативности за счет использования творческих спаррингов и кейсов, ролевых и бизнес-игр, мозговых штурмов, информационных блоков и т.д.

Курс по развитию креативности «От Идеи До Результата» является дистанционным и краткосрочным [3]. В целом данный курс является теоретическим, практическая же часть заключается в выполнении домашних заданий после каждого занятия. На наш взгляд развитие креативности должно включать лекционные занятия и значительное количество практических занятий, на которых участники могли бы сначала под руководством педагога, затем самостоятельно познакомиться с различными методами развития креативности.

Следующий курс называется «Реальное повышение креативности» и он был разработан Еленой Лазаревой, преподавателем Сейнт-Мартинс Колледжа [4]. Курс является универсальным и представляет собой просмотр презентаций, анализ и решение участниками нестандартных дизайнерских задач. Лекционный материал курса содержит информацию: о техниках продуцирования идей; творческих подходах известных дизайнеров, художников, музыкантов, ученых; факторах, блокирующих креативность. Познакомившись с материалами курса, отметим «сильный» момент курса, который заключается в игровой атмосфере на занятиях, которая раскрепощает участников и дает возможность мыслить свободно.

Далее рассмотрим проект MOST Creative Camp, который объединяет выездные лагеря для взрослых, воркшопы для компаний, открытые лекции и онлайн-образование. Данный проект был создан Даниилом Филином и Соломоном Шлосманом, которые утверждают, что на деле креативное мышление не дар и не навык, его можно изучать и тренировать [2]. Агентство устраивает летние практики для студентов-рекламистов, и проводит воркшопы для компаний. В агентстве разработана своя методика развития креативного мышления, в основу которой легли исследования в области креативности, личный опыт и наработки существующих в мире школ креативного мышления. Из собранных материалов особое внимание было уделено работам американского исследователя структуры интеллекта Дж. Гилфорда, Э.П. Торранса и Э. де Боно. Данное агентство находятся в постоянном развитии и изменении своих программ. Большинство модулей рассчитаны на широкую аудиторию. Ключевыми моментами данных модулей является игровая атмосфера на занятиях, дифференцированный подход к участникам.

Следующий рассматриваемый нами курс «Развитие креативности» будет полезен для иллюстраторов, декораторов, стилистов, художников-постановщиков, фотографов, дизайнеров одежды и интерьеров, фильммейкеров, скульпторов, флористов, людей любой другой творческой профессии, которые хотят зарядиться вдохновением, развить навык придумывания идей и оригинальных визуальных решений для своей работы [19]. Подход организаторов опирается на дизайнерский опыт развития визуального языка образного восприятия и постижение законов композиционного моделирования, который трансформирует обыденное сознание, разрушает его стереотипы, учит воспринимать сущность предметов через гармоничный облик. Организаторы утверждают, что способностью не просто смотреть, а видеть и визуализировать такие категории как равновесие, целостность, композиционная организованность обладает каждый. Поэтому специальная, творческая атмосфера с дифференцированным подходом к каждому участнику модуля будет способствовать раскрытию способностей участников культурно-досугового процесса.

Российские культурно-досуговые модули онлайн формата в большинстве своем предполагают просмотр видео материала и самостоятельное выполнение упражнений. Например, «Креативность и интеллект. Развитие творческих и аналитических способностей», который 
не ориентирован на конкретную аудиторию, так как изучаемые в курсе приемы решения задач предназначены для стимулирования умственной деятельности специалистов широкого профиля, связанного с разработкой новых изделий, маркетингом, исследованиями, финансами, человеческими ресурсами или производством и т.д. [7].

Наибольшую эффективность несут культурно-досуговые модули с практическим участием, где присутствует теоретический блок, но большая часть посвящена практике. Креативное мышление формируется в процессе тренировки, и чем длительнее эта тренировка, тем эффективнее формируется продуктивный уровень креативности. Поэтому в процессе культурно-досуговой деятельности по развитию креативности дизайнеров нужно учить инструментам, которые позволяют тренировать креативность в течение жизни.

Таким образом приходим к следующим выводам. На основе анализа отечественного и зарубежного опыта мы нами были выделены основные принципы развития креативности, среди которых:

- принцип преемственности, последовательности, и системности процесса развития креативности дизайнеров;

- принцип связи теории с практикой;

- принцип дифференцированного подхода к участ- нику социокультурной деятельности с свободой выбора индивидуальной творческой траектории;

- принцип активности дизайнеров в эмоционально-насыщенном социокультурном процессе.

Реализация перечисленных принципов будет способствовать наиболее продуктивному процессу развития креативности в условиях культурно-досуговой деятельности. При этом отметим, что отличий между зарубежными и отечественными досуговыми модулями развития креативности нами не были выявлены.

Таким образом, обзор состояния российской практики развития креативности, педагогический опыт в вузе и профессиональный опыт автора в сфере дизайна показывает нехватку креативных качеств у студентов и практикующих дизайнеров, необходимость развития этих качеств и недостаточное количество курсов, где можно это сделать. В связи с ситуацией ограниченности аудиторных часов и сложностью внедрения технологии развития креативности в условиях вуза, развитие креативности дизайнеров может происходить в условиях культурно-досуговой деятельности. Поэтому разработка технологии и организация методики развития креативности в условиях культурно-досуговой деятельности являются ответом на возрастающую потребность в развитии креативности не только дизайнеров, но и всех желающих повысить свой уровень креативности.

ЛИТЕРАТУРА

1. Ахмадиева Р.Ш., Хусаинов Б.Р. Дистанционные технологии как фактор формирования открытых социокультурных границ // Вестник МГУКИ. 2018. №6 (86), c.146-150.

2. Афиша Daily // Мозги на прокачку. Кто учит думать не так, как все URL: https://daily.afisha.ru/brain/7673-mozgi-na-prokachku-kto-uchit-dumat-ne-tak-kakvse-1 (дата обращения: 21.02.2020).

3. Будь креативным! // Курс по развитию креативности «0т Идеи До Результата» http://www.becreative.com.ua/creativity-gym (дата 0бращения: 09.07.2018).

4. Международная школа дизайна // Реальное повышение креативности URL: http://designschool.ru/courses/istoriya-i-teoriya-dizajna/realnoe-povysheniekreativnosti/ (дата обращения: 21.12.2018).

5. Северная столица // Тренинги, коучинг URL: https://iocenter.ru/events/training/Upravlencheskie_naviki/15905/ (дата 0бращения: 06.07.2020)

6. Ц Центр подготовки персонала «Фактор-П» // Тренинг креативности «Искусство нестандартно мыслить» URL: https://treningoff.ru/biznes-treningi/treningilichnoj-ehffektivnosti/trening-kreativnosti-iskusstvo-nestandartno-myslit/ (дата обращения: 22.09.2018).

7. Эитариум центр дополнительного образования // Креативность и интеллект: развитие творческих и аналитических способностей URL: http://www. elitarium.ru/course/distancionnyjj_kurs_kreativnost_intellekt (дата обращения: 12.11.2019).

8. Methodological aspects of art criticism competence personalization of art field educated bachelors. Mishina A.V., Yavgildina Z.M., Avramkova I.S. Revista Turismo Estudos \& Práticas. 2019. № S1. C. 184.

9. Michael Johnson Branding: in five and a half steps: the definitive guide to the strategy and design of brand identities / New York, New York: Thames \& Hudson, 2016.

10. Advanced diploma of creative product development // advanced diploma of creative product development URL: https://www.chisholm.edu.au/courses/advanceddiploma/creative-product-development (дата обращения: 12.11.2019).

11. Alexandertaylor // Sales URL: http://www.alexandertaylor.com/ (дата обращения: 06.08.2019).

12. D\&AD // Alexandra Taylor URL: https://www.dandad.org/profiles/person/524498/alexandra-taylor/ (дата обращения: 06.07.2020).

13. D \& AD // D \& AD Creative Training Courses URL: http://www.dandad.org/en/d-ad-professional-development-creative-training-соurses/ (дата обращения: 11.01.2020).

14. D\&AD// 5 top tricks and tips: when Art Direction goes digital URL: https://www.dandad.org/en/d-ad-tips-digital-art-direction-alex-lampe-training-content/ 
(дата обращения: 06.07.2020).

15. Coursera // Brand Identity and Strategy URL: https://www.coursera.org/learn/brand-identity-strategy (дата обращения: 06.07.2020).

16. EDWARD BOCHES // teaching course strategic development URL: http://edwardboches.com/i'm-teaching-a-course-at-boston-university-strategic-creativedevelopment (дата обращения: 11.01.2020).

17. KUNO // express courses URL: https://www.kunonetwork.org/available-courses (дата обращения: 07.02.2019).

18. Odyssey training // Personal development training URL: https://www.odysseytraining.com.au/personal-development-training/creative-thinking-and-problemsolving-course/ (дата обращения: 12.12.2019).

19. One day // Курс «РАЗВИТИЕ КРЕАТИВНОСТИ» URL: http://www.onedayfern.com/blog/kurs-razvitie-kreativnosti(дата обращения: 21.12.2018).

20. Studio Sutherl\& // Work(\&play)shop URL: http://studio-sutherland.co.uk/projects/workplayshop.php (дата обращения: 06.07.2020).

21. The creativity workshop // Unlock your Creativity URL: http://www.creativityworkshop.com/ (дата обращения: 11.11.2019).

22. University of Manitoba // program creative URL: http://umanitoba.ca/faculties/coned/summer/programs/creative.html (дата 0бращения: 12.11.2019).

( Галиуллина Эльмира Ринатовна (galiullina_er@kazgik.ru).

Журнал «Современная наука: актуальные проблемы теории и практики»

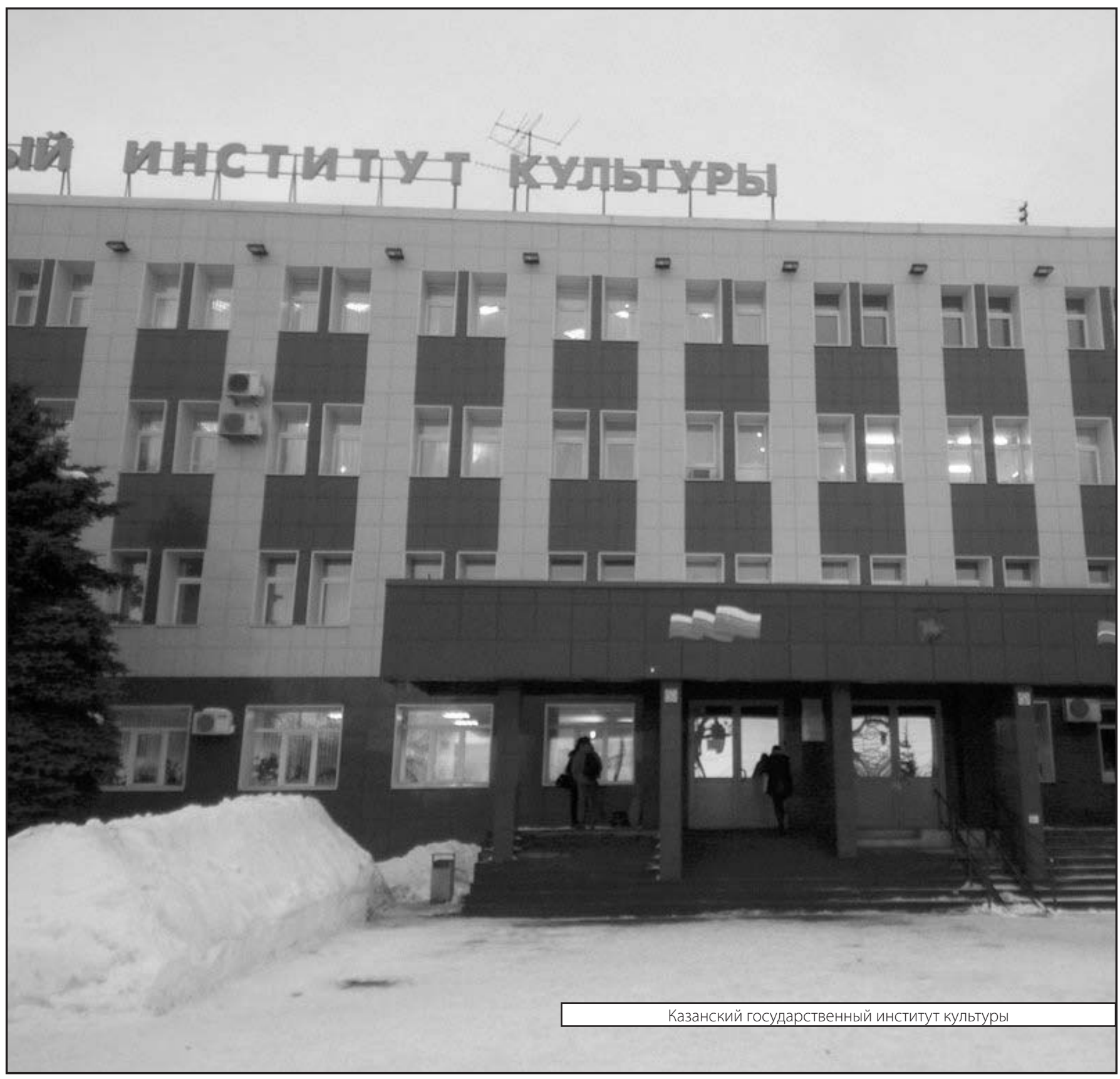

